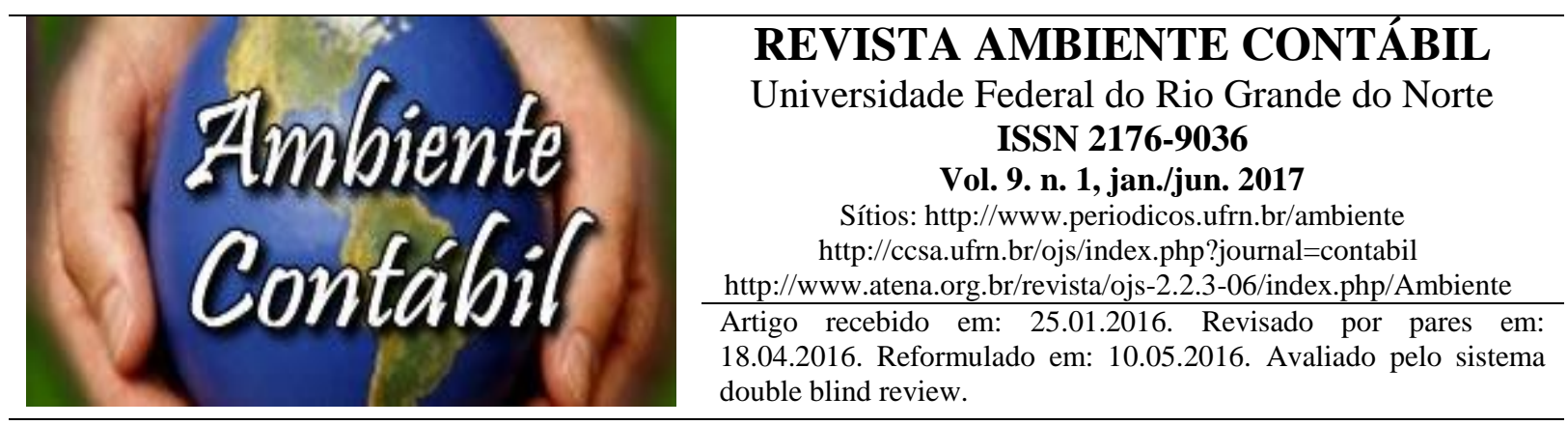

\title{
GESTÃO DE CAPITAL DE GIRO E FORMAÇÃO DO PREÇO DE VENDA PRATICADO PELAS MICRO E PEQUENAS EMPRESAS
}

\section{WORKING CAPITAL MANAGEMENT AND DEVELOPMENT OF THE SELLING PRICE PRACTICED BY MICRO AND SMALL ENTERPRISES}

\section{GESTIÓN DEL CAPITAL DE TRABAJO Y LA FORMACIÓN DEL PRECIO DE VENTA PRACTICADO POR MICRO Y PEQUEÑAS EMPRESAS}

\author{
Autores \\ Olga Graciela Diaz Domingues \\ Mestre em Administração das Micro e Pequenas Empresas pela Faculdade Campo Limpo \\ Paulista - FACCAMP (2015). Endereço: Rua Guatemala, 167, Jardim América, Campo \\ Limpo Paulista - São Paulo - Brasil. CEP: 13231-230. Telefone: (11) 4812-9400 \\ E-mail: olgadomingues@uol.com.br

\section{João Eduardo Prudêncio Tinoco} \\ Doutor em Controladoria e Contabilidade pela Universidade de São Paulo; Pesquisador e \\ Professor do Programa de Mestrado Profissional da FACCAMP - Campo Limpo Paulista - \\ São Paulo - Brasil. Endereço: Rua Guatemala, 167, Jardim América, Campo Limpo Paulista \\ - São Paulo - Brasil. CEP: 13231-230. Telefone: (11) 4812-9400. \\ E-mail: tinocojoao@uol.com.br

\section{Mariano Yoshitake} \\ Doutor em Controladoria e Contabilidade pela Universidade de São Paulo. \\ Mestrado em Administração da Universidade Ceuma. Endereço Rua Josué Montelo, - \\ Renascença II - CEP 65075-120 - São Luis, MA - Brasil. Telefone: (98) 32144165 Ramal: \\ 4165. \\ E-mail: kimimarinamariano@gmail.com \\ Wanderlei Lima de Paulo \\ Doutor em Engenharia Elétrica pela Universidade de São Paulo. Professor do Programa de \\ Mestrado Profissional da FACCAMP - Campo Limpo Paulista. Endereço: Rua Guatemala, \\ 167, Jardim América, Campo Limpo Paulista - São Paulo - Brasil. CEP: 13231-230, \\ Telefone: (11) 4812-9400. \\ E-mail: wldepaulo@gmail.com
}

\section{José Alberto Carvalho dos Santos Claro}

Doutor em Comunicação Social pela Universidade Metodista de São Paulo. Professor Adjunto de Administração no Instituto do Mar, Departamento de Ciências do Mar, da 
Revista Ambiente Contábil - ISSN 2176-9036 - UFRN - Natal-RN. v. 9. n. 1, p. 77 - 96, jan./jun. 2017.

Universidade Federal de São Paulo - UNIFESP. Av. Alm. Saldanha da Gama, 89, Santos, CEP 11030-400, Tel. (13) 3523-5000.

E-mail: albertoclaro@albertoclaro.pro.br

\title{
RESUMO
}

O objetivo deste artigo é verificar se os gestores das micro e pequenas empresas conhecem e utilizam o gerenciamento do Capital de Giro e a precificação de seus produtos, mercadorias e serviços. Visando alcançar esse objetivo, fez-se uma revisão da literatura sobre gestão de capital de giro e formação de preço de venda, investigando-se a amplitude tanto no campo teórico quanto no campo prático. No que concerne, à metodologia realizou-se uma pesquisa de campo com entrevistas face-a-face e semiestruturadas em nove empresas que atuam nos setores comercial, industrial e de serviços, localizadas nos municípios de Jundiaí, Campo Limpo Paulista e Jarinu, pertencentes ao Aglomerado Urbano de Jundiaí. Os resultados da pesquisa revelam que apesar do pouco conhecimento que os empresários têm sobre gerenciamento de capital de giro, a grande maioria (89\%) faz reservas para suprir eventuais dificuldades financeiras. Com relação à precificação de seus produtos, mercadorias e serviços, as empresas adotam o critério de calcular os custos diretos e acrescentar uma margem entre $20 \%$ a $50 \%$. Outro ponto visível nos resultados obtidos foi a falta de orientação dos microempreendedores de seus contadores, levando-os a tomar decisões baseadas, principalmente, mais na intuição e sensibilidade do que no conhecimento.

Palavras-chave: Capital de Giro, Gestão, Preço de Venda, Micro e Pequenas Empresas.

\begin{abstract}
The purpose of this article is to verify that the managers of micro and small businesses know and use management of working capital and the pricing of their products, goods and services. In order to achieve this goal, there was a review of the literature on working capital management and sales pricing, investigating the amplitude both in theory and in practical field. With respect, the methodology was carried out a field survey with face-to-face interviews and semi-structured in nine companies operating in the commercial, industrial and services, located in the municipalities of Jundiai, Campo Limpo Paulista and Jarinu, belonging to Jundiai urban cluster. The survey results reveal that despite the little knowledge that entrepreneurs have on working capital management, the vast majority (89\%) makes reserves to meet possible financial difficulties. With regard to the pricing of their products, goods and services, companies adopt the criteria to calculate the direct costs and add a margin between $20 \%$ and $50 \%$. Another point visible in the results was the lack of guidance that microentrepreneurs of their counters, causing them to make decisions based primarily on intuition and sensitivity more than knowledge.
\end{abstract}

Keywords: Working Capital Management, Selling Price, Micro and Small Enterprises.

\section{RESUMEN}

El propósito de este artículo es verificar que los directivos de las PyMEs conocen y gestión del uso del capital y la fijación de precios de sus productos, bienes y servicios de trabajo. Para lograr este objetivo, se produjo una revisión de la literatura sobre la gestión del capital y los precios de venta, la investigación de la amplitud, tanto en teoría como en la práctica en el campo. Con todo respeto, la metodología se llevó a cabo un estudio de campo con entrevistas cara a cara y semi-estructurada en nueve compañías que operan en los sectores comercial, industrial y de servicios, que se encuentra en los municipios de Jundiaí, Campo Limpo Paulista y Jarinu, perteneciente a grupo urbano Jundiaí. Los resultados de la encuesta revelan que a pesar del poco conocimiento que los empresarios tienen en la gestión del capital, la gran mayoría (89\%) hace que las reservas para cubrir posibles dificultades financieras. En cuanto a 
la fijación de precios de sus productos, bienes y servicios, las empresas adoptan los criterios para el cálculo de los costos directos y añadir un margen de entre el $20 \%$ y el $50 \%$. Otro punto visible en los resultados fue la falta de orientación que los microempresarios de sus contadores, haciendo que se toman decisiones basadas principalmente en la intuición y la sensibilidad más que conocimiento.

Palabras Clave: Gestión de capital de trabajo, Precio Venta, Micro y Pequeñas Empresas.

\section{INTRODUÇÃO}

Assume-se, neste artigo, que as gestões contábil e financeira se relacionam a variáveis contextuais que podem ter influência no desempenho e na atividade das Micro e Pequenas Empresas. Essa hipótese inclui variáveis ligadas à gestão do capital de giro e à precificação de produtos e serviços. Em função do tipo de atividade desenvolvida em cada organização, qualquer uma dessas variáveis pode ter um impacto maior ou menor no seu desenvolvimento em longo prazo.

Assim, discute-se a seguir a natureza de alguns dos participantes envolvidos no apoio às micro e pequenas empresas. Nesse sentido, há apoio governamental expresso em políticas de incentivos fiscais, como o Simples Nacional e o Estatuto Geral das Micro e Pequenas Empresas. O FAT Fomentar - Micro e Pequenas Empresas, por exemplo, foi criado com a finalidade de apoio financeiro para implantação, ampliação, recuperação e modernização, às micro e pequenas empresas de todos os setores da economia, de forma a gerar novas oportunidades de emprego e renda e melhoria da qualidade de vida do trabalhador, bem como contribuir para a competitividade da economia brasileira.

Para propor, acompanhar e gerir os benefícios dispensados às MPEs foram criados dois órgãos que terão atuação fundamental na implantação e na plena consecução da Lei Geral. Veja-se a constituição e as atribuições desses órgãos separadas por assunto:

I - Comitê Gestor de Tributação: vinculado ao Ministério da Fazenda, é composto por representantes da Secretaria da Receita Federal, da Secretaria da Receita Previdenciária, dos estados, do Distrito Federal e dos municípios.

Atribuições: Tratar dos aspectos tributários do Simples Nacional, especialmente da regulamentação de pontos imprescindíveis para boa aplicação do Simples Nacional.

II - Fórum Permanente das Microempresas e Empresas de Pequeno Porte: era presidido e coordenado pelo Ministério do Desenvolvimento, Indústria e Comércio Exterior, contará com a participação dos órgãos federais competentes e das entidades vinculadas ao setor. Atualmente é presidido e coordenado pela Secretaria da Micro e Pequena Empresa.

Atribuições: Tratar dos demais aspectos da lei, devendo, para tanto, orientar e assessorar a formulação e coordenação da política nacional de desenvolvimento das MPEs.

O objetivo do Grupo Temático Micro e Pequenas Empresas, Autogestão e Informalidade, instalado pelo Conselho de Desenvolvimento Econômico e Social (CDES) em setembro de 2003, foi produzir enunciados de políticas públicas que atendam às necessidades e promovam o desenvolvimento das micros e pequenas empresas e empresas de autogestão, com o objetivo de gerar emprego e renda, e inclusão do setor informal da economia.

A Lei Geral é o novo Estatuto Nacional das Microempresas (ME) e das Empresas de Pequeno Porte (EPP). Instituída pela Lei Complementar n. 123, de 14 de dezembro de 2006, veio estabelecer normas gerais relativas ao tratamento diferenciado e favorecido a ser dispensado às MEs e EPPs no âmbito dos Poderes da União, dos Estados, do Distrito Federal e dos Municípios, nos termos dos artigos 146, III, "d", 170, IX e 179 da Constituição Federal. Esta lei sofreu importantes ajustes pelas Leis Complementares 127/2007, 128/ 2008, 133/2009 e pela LC 139/2011 e ficou conhecida como a "Lei Geral das Microempresas e Empresas de Pequeno Porte" ou, mais sucintamente, da "Lei Geral das Micro e Pequenas 
Empresa". MPEs são definidas como as empresas da indústria com até 99 empregados e empresas de comércio e serviços com até 49 empregados (critério operacional do sistema Sebrae). Os dados da seção "Desempenho recente" abrangem apenas a indústria de transformação e consideram como MPEs da indústria as empresas com até 99 empregados e com faturamento anual até $\mathrm{R} \$ 3,6$ milhões (Lei complementar 123/2006). Os dados para o microempreendedor individual (MEI) seguem a legislação sobre o tema.

No Brasil, segundo o Serviço Brasileiro de Apóio às Micro e Pequenas Empresas (SEBRAE, 2012), as MPEs representam aproximadamente 99\% do total de empresas formalmente estabelecidas e, conforme dados do Cadastro Geral de Empregados e Desempregados- CAGED, são responsáveis, em outubro de 2013, por $86 \%$ da geração líquida de empregos, enquanto que as médias e grandes empresas- MGEs respondem por $14 \%$ da geração líquida de empregos, (BRASIL, 2014).

A importância das MPEs para a economia brasileira passa, cada vez mais, a ser reconhecida, principalmente em função do seu papel na geração de empregos, assim, em 1960, conforme Massei (1989), o Banco Nacional de Desenvolvimento Econômico e SocialBNDES toma a iniciativa de organizar um grupo informal de trabalho, formado por técnicos convidados e de seu quadro de funcionários, com intuíto de diagnosticar a situação das MPEs e oferecer alternativas que possam atender suas reivindicações.

O SEBRAE realizou uma pesquisa em 2014 sob o título "Causa Mortis - O sucesso e o fracasso das empresas nos primeiros cinco anos de vida". O objetivo da pesquisa foi identificar os fatores que contribuem para as chances de sucesso (sobrevivência) das empresas, do primeiro ao quinto ano de atividade, no estado de São Paulo. Visou, ademais, conhecer o perfil dos empreendedores e das empresas "jovens" (de um a cinco anos) do estado de São Paulo. A pesquisa foi realizada a partir do rastreamento de 2800 empresas com registro de abertura entre 2007 e 2011, que ocorreu entre 23/04/13 e 30/08/13 e 10/09/13 a 30/11/13. A amostra planejada envolveu dois grupos de empresas: (i) 2000 empresas dos tipos Sociedade Limitado e Empresário, registrados na Junta Comercial do Estado de São Paulo (JUCESP) nos anos de 2007 a 2011; e (ii) 800 microempreendedores individuais (MEI), registrados nos anos de 2010 e 2011. Entre outros destaques, a pesquisa mostrou que:

1. Quanto à origem dos recursos para montar a empresa, 88\% dos empreendedores contaram basicamente com recursos próprios ou da família; quanto aos valores, $58 \%$ dos empreendedores utilizaram até R\$ 10 mil para investimento fixo no negócio; $65 \%$ dos empreendedores utilizaram até $\mathrm{R} \$ 5$ mil para formação de capital de giro;

2. Ao abrir a empresa, parte dos empreendedores não levantou informações relevantes sobre o mercado; $46 \%$ não sabiam o número de clientes que teriam e os hábitos de consumo desses clientes; $39 \%$ não sabiam qual era o capital de giro necessário para abrir o negócio; $38 \%$ não sabiam o número de concorrentes que teriam.

Em razão dos aspectos da contextualização, justificativas e problemas, formula-se a seguinte questão orientadora deste artigo: Os gestores de Micro e Pequenas Empresas conhecem e utilizam o gerenciamento do capital de giro e a precificação de seus produtos, mercadorias e serviços?

$\mathrm{O}$ objetivo do artigo apresenta fins econômicos e financeiros às Micro e Pequenas Empresas (MPEs) e traz uma contribuição acadêmica e científica para a sua área de conhecimento ao tema da pesquisa. Tal contribuição é assegurada pela utilidade do trabalho ao tratar de assuntos contábeis e financeiros, como a gestão do capital de giro e precificação de produtos e serviços. O presente estudo trata de um tema técnico, contudo também possui relevância social em razão de haver interesse da comunidade na geração de emprego e renda, tão necessários ao desenvolvimento regional.

Com base na questão norteadora do estudo, derivam-se os objetivos, geral e específicos. O objetivo geral é verificar se os gestores das MPEs conhecem e utilizam o 
Revista Ambiente Contábil - ISSN 2176-9036 - UFRN - Natal-RN. v. 9. n. 1, p. 77 - 96, jan./jun. 2017.

gerenciamento do Capital de Giro e a precificação de seus produtos, mercadorias e serviços. Os objetivos específicos são:

- Averiguar se há sincronização entre os prazos de pagamento a fornecedores e os prazos de recebimento de clientes;

- Constatar se os gestores têm conhecimento das operações que envolvem o giro dos negócios e se utilizam fluxos de caixa nas empresas e com que periodicidade;

- Identificar os principais critérios utilizados pelas MPEs para determinar o preço de venda de seus produtos, mercadorias e serviços.

\section{REFERENCIAL TEÓRICO}

O referencial teórico é composto por três eixos temáticos que orientam o planejamento deste artigo, delimita os conteúdos abrangidos pelo assunto principal. Assim, definem-se parâmetros a serem seguidos na estruturação do tema de pesquisa. Os eixos temáticos são os seguintes: marco regulatório das MPEs; gestão do capital de giro; formação do preço de venda.

\subsection{MARCO REGULATÓRIO DAS MPES}

Para Viapiana (2001), o momento marcante para as MPEs ocorre em 27 de novembro de 1984, quando é sancionada a Lei n ${ }^{\circ}$ 7.256/1984, denominada Estatuto da Microempresa.

A Constituição Federal de 1988, em seu Título VII (Da Ordem Econômica e Financeira), Capítulo I (Dos Princípios Gerais da Atividade Econômica), dedica o Artigo 179 às Micro e Pequenas Empresas, (BRASIL,1988).

Em 28 de março de 1994, é sancionada a Lei $n^{\circ}$ 8.864/1994, que estabelece normas para as MPEs, relativas ao tratamento diferenciado e simplificado, nos campos: administrativo, fiscal, previdenciário, trabalhista, creditício e de desenvolvimento ambiental (BRASIL, 1994).

Em 5 de dezembro de 1996 é criado o Sistema Integrado de Pagamento de Impostos e Contribuições - Simples Federal, através da Lei no 9.317/1996, redefinindo as condições de enquadramento para as MPEs (BRASIL, 1996).

Em 14 de dezembro de 2006, é criado pela Lei Complementar - LC n ${ }^{\circ} 123 / 2006$, o Simples Nacional, que passa a vigorar a partir de $1^{\circ}$ de julho de 2007 , em substituição ao Simples Federal, (Comitê Gestor do Simples Nacional, pág.5, 2008).

\subsection{GESTÃO DO CAPITAL DE GIRO}

A administração do capital de giro constitui um processo de planejamento e controle dos recursos financeiros aplicados no ativo circulante das empresas. Esses recursos provêm de diversas obrigações a vencer em curto prazo (365 dias), representadas no passivo circulante, e do excedente das exigibilidades de longo prazo e do patrimônio líquido em relação aos ativos não circulantes, qualquer falha nesta área de atuação pode comprometer a capacidade de solvência da empresa e/ou prejudicar a sua rentabilidade. (BRAGA, 1991).

A correta administração do capital de giro é fundamental à boa saúde das empresas, principalmente às MPEs, visto sua importância no desempenho operacional. Uma administração inadequada do capital de giro pode resultar em graves problemas financeiros, podendo levar as MPEs a uma situação de insolvência.

Soares Neto, Pozo e Tachizawa (2011), citando estudos realizados pelo Instituto Global Entrepreneurship Monitor - GEM (2005), afirmam que o Brasil se encontra entre os dez países considerados mais atuantes na atividade empreendedora. Porém, pesquisa realizada 
Revista Ambiente Contábil - ISSN 2176-9036 - UFRN - Natal-RN. v. 9. n. 1, p. 77 - 96, jan./jun. 2017.

pelo SEBRAE em 2010, com 2.008 sócios proprietários e ex-sócios-proprietários, de empresas abertas entre os anos de 2003 a 2007, mostra que 27\% das MPEs, fecham as portas no primeiro ano de vida e somente $42 \%$ conseguem completar cinco anos de vida, (SEBRAE, 2010).

Outro dado importante dessa pesquisa, é que para 45,8\% dos entrevistados, a gestão do Capital de Giro é considerada fundamental para a sobrevivência das MPEs, superando o quesito tributos, citado por $41,7 \%$ dos entrevistados.

Mas o que é gestão do Capital de Giro? Padoveze (2004, p. 112) explicita que a palavra giro refere-se às movimentações contínuas dos negócios da empresa, objetivando, basicamente a formação do lucro. Entende-se, desta forma, que capital de giro é a terminologia utilizada para designar os valores investidos no ativo circulante. Para Souza e Souza (2011), o capital de giro é representado pelos recursos de que uma empresa necessita para financiar suas obrigações ativas, identificadas a partir da compra de matéria prima ou mercadorias até o recebimento pela venda do produto acabado.

Matias (2006) salienta que, para ser eficiente na condução do capital de giro, é necessário ter um foco permanente nos componentes que formam o ativo e o passivo circulante, dispor de um estoque mínimo que atenda à produção, controlar os limites de crédito e as concessões aos clientes, acompanhar os débitos junto a fornecedores e gerenciar o fluxo de caixa, preservando sua liquidez e lucro.

Catelli e Guerreiro (1993) alegam que as empresas, independentemente de seu tamanho, devem praticar a filosofia do Just in Time, ou seja, estoques tendendo a zero, eliminação de tudo que deixe de adicionar valor ao produto, tais como: tempo de inspeção, tempo de espera, tempo de movimentação, tempo de estocagem, o que em outras palavras significa: manter o material certo, na quantidade certa, no lugar certo, no momento certo.

Vários autores têm abordado o tema fluxo de caixa. Para Assaf Neto e Silva (2012), o fluxo de caixa é uma ferramenta financeira de acompanhamento das entradas e saídas de recursos do caixa de uma empresa em um determinado período de tempo. Já, na visão de Yoshitake e Hoji (1997, p.149), o fluxo de caixa é uma ferramenta que representa os aspectos positivos e negativos ao longo do tempo, e sua gestão tem como objetivo consolidar certo nível de liquidez imediata para responder positivamente às incertezas acerca do fluxo de pagamentos e recebimentos. Observam, ainda, que a maioria das empresas quebra, não por falta de lucro, mas sim por falta de caixa.

Até o final do século XX, os estudos estavam mais direcionados para as médias e grandes empresas. É a partir da primeira década do século XXI, que os pesquisadores voltam seu interesse para os problemas financeiros das MPEs e começam a surgir um número maior de pesquisas que tratam da importância da gestão de capital de giro para essas organizações.

No que se refere às pesquisas nacionais, podem-se destacar as realizadas por Sidel e Kume (2003), que destacam a criação de uma Reserva de Capital, denominada por eles de Reserva das Variações de Capital de Giro, como forma de garantir a manutenção do capital físico da empresa, ajustando o lucro passível de distribuição através da contabilização das variações da necessidade de capital de giro. Kassai e Casa Nova (2006), por sua vez, publicam artigo cujo objetivo visa demonstrar como é árdua a tarefa de conseguir empréstimos por parte dos micro e pequenos empresários, para complementar as suas necessidades de capital de giro ou mesmo para novos investimentos. Toledo Filho et al (2010) analisam, através de entrevistas com 135 microempresários, as técnicas administrativas de acompanhamento, avaliação e controle do fluxo de caixa que as microempresas adotam como instrumento de controle gerencial para tomada de decisão.

Por outro lado, a literatura internacional de finanças corporativas é tradicionalmente centrada no estudo das decisões financeiras de longo prazo, porém, Smith (1980), sugere que a gestão do capital de giro é importante por seus efeitos sobre a rentabilidade e risco da 
empresa e, portanto, seu valor. Seguindo essa linha de argumentação, estudos realizados a partir de 1990, têm-se centrado em analisar como a redução de capital de giro pode influenciar a lucratividade das empresas (JOSE, LANCASTER e STEVENS, 1996; SHIN e SOENEN, 1998; DELOOF, 2003; PADACHi, 2006; TERUEL e SOLANO, 2007; e RAHEMAN e NARS, 2007), uma vez que os índices de liquidez tradicionais, embora meçam a capacidade de uma empresa em cumprir suas obrigações, deixam de fornecer informações significativas sob o ponto de vista de fluxo de caixa.

Assim, Cote e Latham (1999) desenvolvem um estudo sobre o impacto dos componentes do capital de giro, como estoque, contas a receber e a pagar, que afetam o nível de caixa. Brigham e Weston (1979, p.209) citam alguns fatores importantes para o capital de giro, como: o tempo dedicado à administração do capital de giro; o investimento em ativos circulantes; a relação entre o crescimento de vendas e os ativos circulantes; e ainda ressaltam sua importância para as pequenas empresas. E, ALShubiri (2011), corroborando com os resultados dos autores anteriormente citados, conclui que o capital de giro é um importante componente de gestão financeira, porque trata de ativos e passivos correntes.

\subsection{FORMAÇÃO DO PREÇO DE VENDA}

O momento da fixação de preço para vender produtos, mercadorias e serviços é crucial para a sobrevivência e a prosperidade do negócio, portanto a fixação do preço de venda está diretamente relacionada com todo o planejamento da empresa, razão pela qual devem ser consideradas as características do segmento de atuação, perfil dos clientes, a estrutura da empresa, os custos e despesas envolvidos na produção e comercialização dos produtos, mercadorias e serviços, a qualidade e a garantia dos produtos, mercadorias e serviços, bem como a intenção de retorno do capital investido.

Como estabelecer o preço de venda dos produtos, mercadorias e serviços? Esta decisão pode ser respondida sob três aspectos: Custos e Despesas, Competitividade e Rentabilidade. Assim, se esses três aspectos estiverem em harmonia, pode-se pensar que se está diante de uma empresa de sucesso. Será?

No dia a dia, verificam-se diversas situações que podem influenciar diretamente essa harmonia, tais como: a empresa não conseguir tratar adequadamente os custos e as despesas, ter perda da competitividade e a rentabilidade estar tão comprometida podendo representar resultados negativos para a empresa, (SEBRAE, 2004).

Sabe-se que as grandes empresas contam com equipes de especialistas que auxiliam a gestão na tomada de decisão. E as MPEs que atitudes adotam? Kassai (1997) explica que é comum o micro e pequeno empreendedor evitar a ajuda de especialistas por crer que ninguém está interessado em estudar os problemas de uma pequena empresa, ou ainda, por uma questão econômica, já que isso pode representar uma elevação nos custos para a empresa.

Stroeher e Freitas (2008) observam que os pequenos empresários têm dificuldades relacionadas à gestão da empresa, tais como: incorreta interpretação do lucro contábil, falta de conhecimento administrativo, falta de conhecimento legal, falta de conhecimento de organização contábil, não distinção entre operações da vida empresarial e da vida particular, entre outras.

Além da falta de informações adequadas, as MPEs convivem com outro problema, o ICMS devido pelo regime de substituição tributária progressiva. Pereira et al (2012) argumentam que o novo sistema de cobrança do ICMS Substituição Tributária Progressiva acarreta para a maioria das empresas um aumento repentino dos custos e em consequência, aumento dos preços para o consumidor final, implicando em um desembolso de recursos financeiros para efetuar o recolhimento relativo a produtos que ainda estão em estoque. 
Como então definir 'preço' e seu papel na economia? Monroe (1992, p. 5 e 6), define preço como sendo "a quantidade de dinheiro que deve ser sacrificada para se adquirir o que se deseja, ou seja, considera o preço como a relação formal que indica a quantidade de dinheiro, bens ou serviços necessários para se adquirir uma determinada quantidade de bens e/ou serviços".

Segundo o autor, em uma economia de mercado, os preços proporcionam as guias que indicam como devem ser utilizados os recursos, são eles que determinam que produtos e/ou serviços devem ser produzidos, em que quantidade e para quem produzir, afetando o comportamento das receitas e despesas. Para as empresas, os benefícios são determinados pela diferença entre as receitas e as despesas, portanto, as receitas são obtidas multiplicandose o preço unitário do bem pelo total de unidades vendidas. Outro fator importante numa economia de mercado é a mudança de preços, por exemplo, quando a quantidade demandada de um determinado produto ou serviço é maior que a oferta, os compradores "empurram" o preço para cima, por outro lado, se a oferta é maior que a demanda, os preços tendem a cair.

Entre os elementos que compõem o preço de venda encontram-se os custos e as despesas.

Callado, Miranda e Callado (2003) destacam que um sistema de custos bem organizado e apropriado aos objetivos da empresa, evidencia o que está acontecendo, servindo de base para a administração tomar decisões sobre a forma de alocar os recursos disponíveis, com o objetivo de otimizar os resultados, já que representa uma ferramenta de auxílio para o gestor tomar decisões objetivando: determinar o custo dos produtos como um dos critérios da fixação de preços; analisar a rentabilidade das diversas atividades e produtos da firma; avaliar os estoques; determinar a estrutura de custos dos produtos e compará-la com a concorrência, bem como empregar os recursos onde produzam melhores resultados.

Todavia, na elaboração do preço de venda, não basta conhecer somente os custos e as despesas. No entendimento de Tinoco (2014), é necessário que a empresa conheça sua demanda, e esclarece que junto ao conhecimento de como o preço influi na percepção de valor dos compradores, deve-se conhecer como utilizam o produto ou o serviço. Isto porque se o produto representa um custo importante no processo produtivo do cliente, pequenas alterações de preço podem afetar os custos e consequentemente, o seu preço de produção.

Assim, infere-se que o preço de venda de um bem ou serviço, primeiramente, deverá ser capaz de cobrir todos os custos e despesas, inclusive aqueles que parecem "invisíveis", tais como taxas de entrega, armazenamento, taxas e impostos, inclusive anuais, entre outros. Deverá ser capaz de fornecer lucro para a empresa, que, na prática, é o valor que sobra da venda do bem ou serviço após serem deduzidos os custos/despesas da mercadoria vendida, do trabalho, despesas fixas e variáveis e outras operacionais e administrativas.

Outro item importante a ser observado pelo empreendedor, a fim de conseguir um valor justo e competitivo, é a realização de uma pesquisa de mercado. Essa pesquisa possibilitará saber quanto a concorrência está cobrando e desta forma ter uma referência de quanto ele deve cobrar por seu bem ou serviço. Feito isso, o passo seguinte é verificar que tipo de bem ou serviço está sendo oferecido, uma vez que o mesmo produto pode ser ofertado de formas distintas e para públicos diversos (MONROE 1992).

Conhecer o perfil do cliente e levar em conta as condições de venda, também ajuda a elaborar o preço de venda. Assim, dependendo do cliente, o empreendedor deve oferecer produtos, mercadorias e/ou serviços diferenciados ou que agreguem algum valor (MONROE 1992). O autor explicita, ademais, no que tange às vendas, é importante conhecer o volume de produtos que o cliente está interessado em adquirir, se o volume é grande, o valor deve ser diferenciado, a mesma precaução deve ser tomada com relação às condições de pagamentos, a prazo ou à vista. 
Dentro das pesquisas nacionais, podem-se destacar as realizadas por Santos (1997), que elabora um modelo conceitual de decisão de preço de venda, reconhecendo as limitações de aplicabilidade e contribuições das abordagens existentes até então, enfatizando a utilização do "Preço-Alvo de Mercado" e do "Preço-Alvo de Contribuição", estruturando-o sistemicamente para formulação, análise, mensuração econômica e avaliação das consequências resultantes de alternativas de preços, de forma a otimizar esta decisão. Prado (2007), que pesquisou a dificuldade do economista moderno em entender como Marx e outros economistas clássicos pensam a formação de preço. Com base na distinção entre microeconomia reducionista e microeconomia sistêmica, compara esse modo com aquele da teoria neoclássica, examinando em sequência três tipos de representações da formação de preços: o mercado como coerência, o mercado como equilibrismo e o mercado como processo. Azevedo e Politi (2008) caracterizaram o padrão de concorrência no mercado de leite fluido (longa vida e pasteurizado), a partir de evidências sobre os movimentos de preços no varejo e do comportamento das margens de mercado.

Por outro lado, Braga, Braga e Souza (2010) analisam as questões relacionadas à gestão dos estoques, do capital de giro, do processo de formação de preços, e da gestão de custos em indústrias conserveiras do estado do Rio Grande do Sul. Resende Filho et al (2011) fazem estudo sobre a precificação da água e sua eficiência técnica em perímetros irrigados. Caldarelli e Bacchi (2012) fazem um estudo sobre o funcionamento do mercado de milho no Brasil, objetivando investigar os fatores que afetam as quantidades comercializadas e os preços do milho no mercado brasileiro.

No âmbito internacional, além de Monroe (1992) já citado destacam-se: Dolan (1987), que preocupado com a postura dos gerentes de marketing, dispostos a fornecer descontos indiscriminadamente, na ânsia de vender, faz uma revisão bibliográfica, nas áreas de economia e marketing, objetivando especificar as motivações que levam os gestores a tomar atitudes de fornecer descontos sem prévios estudos de mercado e fornecer diretrizes que indiquem aos gestores a melhor "hora" e a quantidade de descontos que podem oferecer ao cliente. Por outro lado, Fishman (2003) conclui em sua pesquisa que a maioria das empresas norte americanas definem seus preços de venda sem prévios estudos.

Seguindo outra linha Morris; Schurink (1993), através de pesquisa realizada em empresas da África do Sul, avaliam o grau em que a turbulência ambiental afeta a formação de preços no comércio e indústria e concluem que o comportamento dos preços é o resultado de uma nova dinâmica no ambiente externo das empresas.

Sainio e Marjakoski (2009) analisam a relação entre preço e estratégia de negócios na indústria de software, entrevistando 23 representantes de empresas de software da Finlândia, e concluem que os níveis estratégicos e operacionais estão fortemente interligados.

\section{PROCEDIMENTOS METODOLÓGICOS}

\subsection{CARACTERIZAÇÃO DA PESQUISA}

Do ponto de vista de sua natureza, trata-se de pesquisa aplicada, considerando-se que está direcionada para a obtenção de conhecimento com vistas à aplicação prática e à solução de problemas específicos. Quanto aos objetivos, a pesquisa é descritiva, uma vez que com base nas análises dos questionários, busca-se explicar as estratégias adotadas pelas MPEs para lidarem com seus problemas econômicos e financeiros relativos à gestão do capital de giro e calcular o seu preço de venda. Quanto à abordagem do problema, a pesquisa é enquadrada como qualitativa.

De acordo com Godoy (1995, p.21), “Algumas características básicas identificam os estudos denominados qualitativos". Para a citada autora (1995, p.21), segundo esta 
perspectiva, um fenômeno pode ser mais bem compreendido no contexto em que ocorre do qual é parte, devendo ser analisado numa perspectiva integrada. Continuando, a autora afirma que "Para tanto, o pesquisador vai a campo buscando captar o fenômeno em estudo a partir da perspectiva das pessoas nele envolvidas, considerando todos os pontos de vista relevantes". Afirma a referida autora, que "vários tipos de dados são coletados e analisados para que se entenda a dinâmica do fenômeno. Partindo de questões amplas que vão se aclarando no decorrer da investigação o estudo qualitativo pode, no entanto, ser conduzido através de diferentes caminhos".

\subsection{POPULAÇÃO, AMOSTRA E COLETA DE DADOS}

No que concerne ao procedimento técnico, é uma pesquisa de campo, realizada mediante entrevistas face-a-face, semiestruturadas, com questões abertas e fechadas.

A pesquisa de campo foi realizada em nove MPEs localizadas no Aglomerado Urbano de Jundiaí que é formado por sete municípios: Cabreúva, Campo Limpo Paulista, Itupeva, Jarinu, Jundiaí, Louveira e Várzea Paulista. A Estatística da Aglomerado Urbano de Jundiai apresenta a seguinte situação em 2010:

\section{Quadro 1 - Número de estabelecimentos do Aglomerado Urbano de Jundiaí}

\begin{tabular}{|l|r|r|}
\hline & $\mathbf{2 0 1 0}$ & No. Empregos \\
\hline Estabelecimentos industriais & 2.500 & 98.500 \\
\hline Estabelecimentos comerciais & 5.700 & 51.000 \\
\hline Estabelecimentos de serviços & 5.000 & 95.000 \\
\hline Total & $\mathbf{1 3 . 2 0 0}$ & $\mathbf{2 4 4 . 5 0 0}$ \\
\hline
\end{tabular}

Emplasa - http://consultaemplasa.sustentare.org/consulta_arquivos/roteiro_jundiai.pdf

Utilizou-se da amostragem não probabilística, especificamente a amostragem por julgamento em razão de algumas micro e pequenas empresas serem selecionadas intencionalmente. Essa seleção é feita considerando que "a amostra poderá oferecer as contribuições solicitadas." (CHURCHILL, p. 301). Hansen, Hurwitz e Madow (p. 72) concordam que o método de amostras por julgamento é enviesado, e argumentam que o viés provavelmente poderá ser menor se forem selecionadas mais de uma localidade. Nesse sentido, foram selecionadas sete diferentes localidades (municípios do Aglomerado Urbano de Jundiaí). Por meio da revisão de literatura, percebe-se que a amostragem não probabilística pode ser usada em pesquisas acadêmicas e pesquisas de mercado. (OLIVEIRA, 2001). De acordo com a referida autora, esse uso traz contribuições aos estudos nos quais ela é empregada, desde que seja utilizada em determinadas situações e suas limitações sejam consideradas.

A coleta dos dados se realiza através de entrevistas, compostas de três blocos, sendo o primeiro para obtenção dos dados pessoais. O segundo referente aos dados empresariais. O terceiro para obtenção dos dados financeiros das empresas onde se procurou detectar e analisar se os gestores mantêm sincronização entre os prazos de pagamentos a fornecedores e os recebimentos de clientes, bem como, qual é o grau de conhecimento que possuem das operações que envolvem o giro dos negócios, se fazem uso de fluxos de caixa e com que periodicidade e constatar e analisar os critérios por eles utilizados na hora de precificar seus produtos, mercadorias e serviços.

Realizada no Aglomerado Urbano de Jundiaí- AUJ, localizado entre as regiões metropolitanas de São Paulo e Campinas, é uma das mais recentes unidades das 49 regionais do Estado de São Paulo, criado através do Projeto de Lei Complementar no 13/2011 e 
sancionado pelo governo do estado em 24 de agosto de 2011. O AUJ é composto pelos municípios de Jundiaí, Várzea Paulista, Campo Limpo Paulista, Jarinu, Cabreúva, Louveira e Itupeva, com uma população estimada de 700 mil habitantes, sendo que 53\% dessa população concentram-se no município de Jundiaí, localizado em um entroncamento rodoferroviário importante, entre as regiões de Campinas e São Paulo, e o Aglomerado Urbano de Sorocaba (FANELLI e SANTOS Jr, 2013).

\subsection{ANÁLISE E INTERPRETAÇÃO DE DADOS}

A análise é desempenhada a partir da organização e sumário dos dados da pesquisa que permitirão o fornecimento de respostas ao problema e objetivos formulados para a presente investigação. Procura-se com a análise a formação de sentido além dos dados e esta formação dá-se pela consolidação, limitação e interpretação das respostas das pessoas entrevistadas. Trata-se da procura de significados com utilização de técnicas de análise de dados na pesquisa qualitativa e confronto com as teorias existentes a respeito do assunto investigado. Evidenciam-se, dessa forma, as teorias e fatos que envolvem os dados coletados para, assim, tirar conclusões a respeito. Esta etapa objetiva vincular os fundamentos teóricos ao que realmente se observou na pesquisa.

\section{APRESENTAÇÃO E ANÁLISE DOS DADOS}

O primeiro bloco (dados pessoais) mostra o grau de instrução dos sócios, dos nove gestores participantes, oito possuem, no mínimo, curso superior completo.

Com relação aos dados empresariais, seis empresas são optantes do Simples Nacional e três optantes do Lucro Presumido. Verifica-se também que o setor industrial é o que tem o maior número de colaboradores, representando $67 \%$ do total de pessoal contratado por essas MPEs, seguidas pelo comércio, responsável por $25 \%$ das contratações e, por último os serviços, com apenas $8 \%$ de mão de obra contratada. Aqui vale esclarecer que duas das empresas de serviços entrevistadas atuam na produção de vídeos corporativos e de publicidade, trabalhando com equipes terceirizadas, as quais são contratadas de acordo com as necessidades de cada projeto.

Outro dado verificado é que todas as empresas do setor industrial e de serviços, participantes da pesquisa, fazem investimentos em qualificação profissional para seus colaboradores e sócios, enquanto que no setor comercial, somente uma das empresas entrevistadas financia cursos de aperfeiçoamento profissional para colaboradores e sócios, contudo, todas as empresas entrevistadas alegam investir em novas tecnologias.

Analisando-se as respostas fornecidas, percebe-se que das nove empresas entrevistadas, oito possuem algum tipo de assessoria, seja financeira, contábil ou do SEBRAE. Com relação à necessidade de recorrer a terceiros para superar déficits financeiros, todas alegaram terem em algum momento feito, no mínimo, empréstimos bancários, e duas delas com taxas de juros bem altas, o que pode levá-las à insolvência, como é comum em empresas desse porte.

Outro dado importante é que somente três empresas alegam fazer algum tipo de investimento, que é a poupança, demonstrando que necessitam de uma melhor assessoria financeira para bem conduzir suas atividades, já que, como se sabe, aplicações em caderneta de poupança, no Brasil, não geram juros reais, inclusive presentemente, em 2015, os juros nominais de $0,5 \%$ ao mês, correspondentes a $6,17 \%$ ao ano são inferiores à inflação mensal atual e esperada.

A pesquisa de campo, realizada em nove empresas atuantes nos setores comercial, industrial e de serviços, possibilitou atender aos objetivos geral e específicos. 
Revista Ambiente Contábil - ISSN 2176-9036 - UFRN - Natal-RN. v. 9. n. 1, p. 77 - 96, jan./jun. 2017.

- Averiguar se há sincronização entre os prazos de pagamento a fornecedores e os prazos de recebimento de clientes;

Verificou-se que $78 \%$ das MPEs entrevistadas mantêm sincronização entre os prazos de pagamento a fornecedores e os prazos de recebimento de clientes.

- Determinar os principais critérios utilizados pelas MPEs para determinar o preço de venda de seus produtos, mercadorias e serviços.

Quanto à precificação de seus produtos, mercadorias e serviços, verificou-se que todas as empresas adotam o critério de calcular os custos diretos e acrescentar uma margem que, no caso das MPEs entrevistadas, varia de $20 \%$ a $50 \%$. Três dessas empresas alegaram que possuem o hábito de fazer pesquisa de mercado e somente duas afirmaram incluir no cálculo do preço de venda, além dos custos diretos, os custos indiretos, as despesas fixas, os impostos e fretes.

- Constatar se os gestores têm pleno conhecimento das operações que envolvem o giro dos negócios e se utilizam fluxos de caixa na empresa e com que periodicidade;

Constatou-se também que, apesar da maioria dos entrevistados terem alegado conhecer as operações que envolvem o giro dos negócios, não sabem como utilizar as ferramentas disponíveis para gerenciamento do capital de giro. Dos $89 \%$ que alegaram utilizar fluxo de caixa, 38\% afirmaram que não sabem a utilidade dessa ferramenta e fazem esse controle por obrigação, já que atuam sob o regime de Lucro Presumido, tornando-a item obrigatório na empresa. Todavia, notou-se que, apesar do pouco conhecimento sobre o gerenciamento do giro dos negócios, a grande maioria procura manter reservas monetárias para eventuais emergências. Outra particularidade é que, salvo a indústria B e o comércio A, as demais MPEs fornecem a seus sócios pró-labore previamente estipulado.

\subsection{PROPOSIÇÕES}

Com base no referencial teórico e nos resultados da pesquisa de campo, alguns pontos precisam ser frisados no tangente ao gerenciamento do capital de giro e a formação do preço de venda praticado por essas MPEs.

\subsection{PROPOSIÇÕES PARA O CAPITAL DE GIRO}

Manter uma reserva financeira para cobrir eventuais emergências é importante, todavia, outras medidas simples podem ser tomadas pelos gestores no intuito de eliminar ou pelo menos prevenir a insuficiência de capital de giro.

Entre essas medidas, podem ser destacadas:

1. O controle da inadimplência;

2. Evitar financiar o capital de giro a qualquer custo, como por exemplo, deixando de fazer empréstimos com juros elevados;

3. Negociar um prazo maior para pagamento de suas dívidas, desde que o custo desse prolongamento possa ser suportado pela rentabilidade da empresa;

4. Manter controles rígidos sobre as contas a receber, evitando que os recebimentos ocorram em datas posteriores aos vencimentos das duplicatas a pagar;

5. Reduzir os custos, identificando itens que possam ser cortados sem grandes prejuízos para a empresa e ainda;

6. Encurtar o ciclo operacional;

7. Para as indústrias, reduzir o tempo de produção significa encurtar o prazo de vendas;

8. Para o comércio, reduzir o ciclo operacional significa um giro mais rápido dos estoques e para os serviços, equivale a trabalhar com prazos mais curtos; 
Revista Ambiente Contábil - ISSN 2176-9036 - UFRN - Natal-RN. v. 9. n. 1, p. 77 - 96, jan./jun. 2017.

9. Gerenciar e controlar o fluxo de caixa.

\subsection{PROPOSIÇÕES PARA A FORMAÇÃO DO PREÇO DE VENDA}

Por outro lado, na precificação de produtos, mercadorias e serviços, é importante que o gestor das MPEs esteja ciente de que o preço de venda deve ser capaz, primeiramente, de cobrir todos os custos e despesas, inclusive taxas de entrega, armazenamento, impostos entre outros, neste sentido, a pesquisa revelou que $67 \%$ das MPEs entrevistadas não utilizavam planilhas de custo e que estes eram calculados por aproximação.

Outro ponto importante a ser considerado é que o preço de venda deverá também ser capaz de fornecer lucro para a empresa, evitando que esta seja obrigada a recorrer a terceiros para superar déficit financeiro e ainda, com a finalidade de conseguir um valor justo e competitivo é aconselhável que o gestor faça uma pesquisa de mercado para saber quanto a concorrência está cobrando e desta forma obter uma referência de quanto deverá cobrar por seu produto, por sua mercadoria ou serviço.

\subsection{ASSESSORAMENTO CONTÁBIL-FINANCEIRO}

Considera-se que o sucesso empresarial está ligado a um bom gerenciamento do capital de giro e a sensibilidade e competência do gestor na hora da precificação de produtos, mercadorias e serviços.

Pode-se concluir, com base na pesquisa que, apesar de todas as MPEs entrevistadas estarem atuando no mercado há mais de cinco anos, os gestores têm necessidade de contar com um assessoramento contábil-financeiro de qualidade. Que essa assessoria lhes demonstre a importância do fluxo de caixa, bem como o de manter um controle rígido sobre os estoques, sobre as duplicatas a receber e a pagar no gerenciamento do capital de giro. É preciso também orientá-los quanto à utilização de controles, como fichas de custos, mapeamento dos preços praticados pela concorrência, entre outras, que poderão facilitar o processo de precificação de seus produtos, mercadorias e serviços.

Apresenta-se, a seguir, o quadro 2 onde se faz a ligação entre o recorte teórico utilizado neste trabalho e as "Proposições" apresentadas para o preço de venda e capital e giro. Esse quadro foi denominado de Amarração: autores referenciados ligados às Proposições.

Quadro 2 - AMARRAÇÃO: Autores referenciados ligados às Proposições

\begin{tabular}{|c|c|c|}
\hline AUTORES & & PROPOSIÇÕES \\
\hline BRAGA, 1991 & $\begin{array}{l}\text { Qualquer falha na administração } \\
\text { do capital de giro pode } \\
\text { comprometer a capacidade de } \\
\text { solvência da empresa e/ou } \\
\text { prejudicar a sua rentabilidade. }\end{array}$ & 1. O controle da inadimplência; \\
\hline $\begin{array}{l}\text { Soares Neto, Pozo e Tachizawa } \\
\text { (2011), citando estudos } \\
\text { realizados pelo Instituto Global } \\
\text { Entrepreneurship Monitor - } \\
\text { GEM (2005). }\end{array}$ & $\begin{array}{l}\text { Para } 45,8 \% \text { dos entrevistados, a } \\
\text { gestão do Capital de Giro é } \\
\text { considerada fundamental para a } \\
\text { sobrevivência das MPEs, } \\
\text { superando o quesito tributos, } \\
\text { citado por } 41,7 \% \text { dos } \\
\text { entrevistados. }\end{array}$ & $\begin{array}{l}\text { Manter uma reserva financeira } \\
\text { para cobrir eventuais } \\
\text { emergências é importante, } \\
\text { todavia, outras medidas simples } \\
\text { podem ser tomadas pelos } \\
\text { gestores no intuito de eliminar } \\
\text { ou pelo menos prevenir a } \\
\text { insuficiência de capital de giro. }\end{array}$ \\
\hline Matias (2006) & $\begin{array}{l}\text { Para ser eficiente na condução } \\
\text { do capital de giro, é necessário } \\
\text { ter um foco permanente nos } \\
\text { componentes que formam o }\end{array}$ & $\begin{array}{l}\text { 2. Evitar financiar o capital de } \\
\text { giro a qualquer custo, como por } \\
\text { exemplo, deixando de fazer } \\
\text { empréstimos com juros }\end{array}$ \\
\hline
\end{tabular}


Revista Ambiente Contábil - ISSN 2176-9036 - UFRN - Natal-RN. v. 9. n. 1, p. 77 - 96, jan./jun. 2017.

\begin{tabular}{|c|c|c|}
\hline & $\begin{array}{l}\text { ativo e o passivo circulante, } \\
\text { dispor de um estoque mínimo } \\
\text { que atenda à produção, controlar } \\
\text { os limites de crédito e as } \\
\text { concessões aos clientes, } \\
\text { acompanhar os débitos junto a } \\
\text { fornecedores e gerenciar o fluxo } \\
\text { de caixa, preservando sua } \\
\text { liquidez e lucro }\end{array}$ & $\begin{array}{l}\text { elevados; } \\
\text { 4. Manter controles rígidos sobre } \\
\text { as contas a receber, evitando que } \\
\text { os recebimentos ocorram em } \\
\text { datas posteriores aos } \\
\text { vencimentos das duplicatas a } \\
\text { pagar. } \\
\text { 9. Gerenciar e controlar o fluxo } \\
\text { de caixa. }\end{array}$ \\
\hline Catelli e Guerreiro (1993) & $\begin{array}{l}\text { As empresas, } \\
\text { independentemente de seu } \\
\text { tamanho, devem praticar a } \\
\text { filosofia do Just in Time, ou seja, } \\
\text { estoques tendendo a zero, } \\
\text { eliminação de tudo que deixe de } \\
\text { adicionar valor ao produto, tais } \\
\text { como: tempo de inspeção, tempo } \\
\text { de espera, tempo de } \\
\text { movimentação, tempo de } \\
\text { estocagem, o que em outras } \\
\text { palavras significa: manter o } \\
\text { material certo, na quantidade } \\
\text { certa, no lugar certo, no } \\
\text { momento certo. }\end{array}$ & $\begin{array}{l}\text { 6. Encurtar o ciclo operacional. } \\
\text { 7. Para as indústrias, reduzir o } \\
\text { tempo de produção significa } \\
\text { encurtar o prazo de vendas. } \\
\text { 8. Para o comércio, reduzir o } \\
\text { ciclo operacional significa um } \\
\text { giro mais rápido dos estoques e } \\
\text { para os serviços, equivale a } \\
\text { trabalhar com prazos mais } \\
\text { curtos. }\end{array}$ \\
\hline $\begin{array}{l}\text { Assaf Neto e Silva (2012) } \\
\text { e Yoshitake e Hoji (1997, } \\
\text { p.149). }\end{array}$ & $\begin{array}{l}\text { O fluxo de caixa é uma } \\
\text { ferramenta financeira de } \\
\text { acompanhamento das entradas e } \\
\text { saídas de recursos do caixa de } \\
\text { uma empresa em um } \\
\text { determinado período de tempo } \\
\text { (Assaf Neto e Silva, 2012). } \\
\text { O fluxo de caixa é uma } \\
\text { ferramenta que representa os } \\
\text { aspectos positivos e negativos ao } \\
\text { longo do tempo, e sua gestão } \\
\text { tem como objetivo consolidar } \\
\text { certo nível de liquidez imediata } \\
\text { para responder positivamente às } \\
\text { incertezas acerca do fluxo de } \\
\text { pagamentos e recebimentos. } \\
\text { Observam, ainda, que a maioria } \\
\text { das empresas quebra, não por } \\
\text { falta de lucro, mas sim por falta } \\
\text { de caixa. } \\
\text { Yoshitake e Hoji (1997, p.149). }\end{array}$ & $\begin{array}{l}\text { 1. O controle da inadimplência; } \\
\text { 2. Evitar financiar o capital de } \\
\text { giro a qualquer custo, como por } \\
\text { exemplo, deixando de fazer } \\
\text { empréstimos com juros } \\
\text { elevados; } \\
\text { 3. Negociar um prazo maior para } \\
\text { pagamento de suas dívidas, } \\
\text { desde que o custo desse } \\
\text { prolongamento possa ser } \\
\text { suportado pela rentabilidade da } \\
\text { empresa. } \\
\text { 9. Gerenciar e controlar o fluxo } \\
\text { de caixa. }\end{array}$ \\
\hline $\begin{array}{l}\text { Smith, 1980, } \\
\text { Jose; Lancaster e Stevens, 1996; } \\
\text { Shin e Soenen, 1998; Deloof, } \\
\text { 2003; Padachi, 2006; Teruel e } \\
\text { Solano, 2007; e Raheman e } \\
\text { Nars, 2007. }\end{array}$ & $\begin{array}{l}\text { Smith (1980), sugere que a } \\
\text { gestão do capital de giro é } \\
\text { importante por seus efeitos sobre } \\
\text { a rentabilidade e risco da } \\
\text { empresa e, portanto, seu valor. } \\
\text { Seguindo essa linha de } \\
\text { argumentação, estudos } \\
\text { realizados a partir de } 1990 \text {, têm- } \\
\text { se centrado em analisar como a } \\
\text { redução de capital de giro pode } \\
\text { influenciar a lucratividade das } \\
\text { empresas }\end{array}$ & $\begin{array}{l}\text { 9. Gerenciar e controlar o fluxo } \\
\text { de caixa. }\end{array}$ \\
\hline
\end{tabular}

Fonte: elaborado pelos autores. 
Revista Ambiente Contábil - ISSN 2176-9036 - UFRN - Natal-RN. v. 9. n. 1, p. 77 - 96, jan./jun. 2017.

\section{5- CONSIDERAÇÕES FINAIS}

A questão norteadora do artigo faz a seguinte asserção: Os gestores de Micro e Pequenas Empresas conhecem e utilizam o gerenciamento do capital de giro e a precificação de seus produtos, mercadorias e serviços? Essa questão norteadora foi convertida em um objetivo específico que procura constatar se os gestores têm pleno conhecimento das operações que envolvem o giro dos negócios e se utilizam fluxos de caixa na empresa e com que periodicidade.

A pesquisa constatou que, dos $89 \%$ que alegaram utilizar fluxo de caixa, $38 \%$ afirmaram que não sabem a utilidade dessa ferramenta e fazem esse controle por obrigação, já que atuam sob o regime de Lucro Presumido, tornando-a item obrigatório na empresa. $\mathrm{O}$ segundo objetivo especifico averiguou se há sincronização entre os prazos de pagamento a fornecedores e os prazos de recebimento de clientes. A pesquisa identificou que $78 \%$ das MPEs entrevistadas mantêm sincronização entre os prazos de pagamento a fornecedores e os prazos de recebimento de clientes. O terceiro e último objetivo específico procurou determinar os principais critérios utilizados pelas MPEs para determinar o preço de venda de seus produtos, mercadorias e serviços. Como resposta, a pesquisa, quanto à precificação de seus produtos, mercadorias e serviços, verificou que todas as empresas adotam o critério de calcular os custos diretos e acrescentar uma margem que, no caso das MPEs entrevistadas, varia de $20 \%$ a $50 \%$. Três dessas empresas alegaram que possuem o hábito de fazer pesquisa de mercado e somente duas afirmaram incluir no cálculo do preço de venda, além dos custos diretos, os custos indiretos, as despesas fixas, os impostos e fretes.

Pode-se concluir, com base na pesquisa que, apesar de todas as MPEs entrevistadas estarem atuando no mercado há mais de cinco anos, os gestores têm necessidade de contar com um assessoramento contábil-financeiro de qualidade. Que essa assessoria lhes demonstre a importância do fluxo de caixa, bem como o de manter um controle rígido sobre os estoques, sobre as duplicatas a receber e a pagar no gerenciamento do capital de giro. É preciso também orientá-los quanto à utilização de controles, como fichas de custos, mapeamento dos preços praticados pela concorrência, entre outras, que poderão facilitar o processo de precificação de seus produtos, mercadorias e serviços.

As MPEs têm importante papel no desenvolvimento sócio econômico do país, sendo reconhecidas como geradoras da maioria dos empregos formais no Brasil, porém, grande parte dessas empresas fecha as portas antes de completar cinco anos de atividade.

Entre os motivos possíveis para a insolvência, destacam-se dois: o gerenciamento do capital de giro, pois se trata de um dos aspectos mais importantes na gestão financeira da empresa e a formação do preço de venda, crucial para a sobrevivência e prosperidade do negócio.

Com os resultados desta pesquisa descritiva buscou-se contribuir com pesquisadores das áreas contábil, administrativa, financeira e econômica em futuras pesquisas, visto que a aspiração é proporcionar uma análise inicial sobre o conhecimento que os gestores de MPEs têm das operações que envolvem o giro dos negócios, bem como conhecer os critérios utilizados para determinar o preço de venda. Procurou-se também contribuir de alguma forma, com os profissionais da área contábil-financeira que vêm assessorando essas MPEs, visto terem sido expostas as dificuldades que os gestores têm em entender e fazer uso eficiente e eficaz de cada uma das ferramentas disponíveis em prol de suas empresas.

Por fim, visando à continuidade da pesquisa, uma vez que nem todos os aspectos relacionados ao tema foram profundamente tratados, sugere-se que novos estudos sejam realizados, envolvendo um número maior de empresas e outros municípios pertencentes ao 
Revista Ambiente Contábil - ISSN 2176-9036 - UFRN - Natal-RN. v. 9. n. 1, p. 77 - 96, jan./jun. 2017.

Aglomerado Urbano de Jundiaí possibilitando que os resultados obtidos possam ser estendidos a todas as MPEs atuantes nos setores comercial, industrial e de serviços.

\section{REFERÊNCIAS}

ALSHUBIRI, F. N. The Effect of Working Capital Practices on Risk Management: Evidence from Jordan. Global Journal of Business Research, v. 5, n. 1, p. 29-54, 2011.

ASSAF NETO, A.; SILVA, C. A.T. Administração do Capital de Giro- Manual de Exercícios. São Paulo: Atlas, 2012.

ASSAF NETO, Alexandre; SILVA, César Augusto Tibúrcio. Administração do Capital de Giro. São Paulo: Atlas, 1995.

AZEVEDO, P. F. DE, POLITI, R.B. Concorrência e Estratégias de Precificação no Sistema Agroindustrial do Leite. RESR, Piracicaba, SP, vol. 46, nº 03, p. 767-802, jul/set 2008 Impressa em outubro 2008.

BRAGA, D. P. G.; BRAGA, A. X.V.; SOUZA, M. A. Gestão de Custos, Preços e Resultados: um Estudo em Indústrias Conserveiras do Rio Grande do Sul. Contabilidade, Gestão e Governança - Brasília · v. 13 • n. 2 - p. 20 - 35 - mai/ago 2010; ISSN 1984-3925.

BRAGA, R. Análise Avançada do Capital de Giro. Caderno de Estudos FIPECAFI, $n^{\circ} 3$, São Paulo, Setembro/1991.

BRASIL. Constituição da República Federativa do Brasil. $35^{\text {a }}$ edição, 5 de outubro de 1988; Biblioteca digital, http://bd.camara.gov.br. Visitado 25/01/2014.

Lei $N^{\circ}$ 8.864, de 28 de março de 1994. DOU de 28/03/1994. Diário Oficial [da] República Federativa do Brasil. Brasília, DF, 28 de março de 1994.

Lei $N^{\circ} 9.317$ Lei das Microempresas e das Empresas de Pequeno Porte, de 05 de dezembro de 1996. DOU de 06/12/1996. Diário Oficial [da] República Federativa do Brasil. Brasília, DF, 06 de dezembro de 1996.

Dados Estatísticos Gerais- Ministério do Trabalho e Emprego- CAGED- disponível em: http://portal.mte.gov.br/caged/ - visitado em 10/02/2014.

. Receita Federal- Lei Complementar $n^{\circ}$ 147, de 7 de agosto de 2014. Disponível em: <http://www.receita.fazenda.gov.br/Legislacao/LeisComplementares/2014/leicp147.htm>.

Acesso em: 09 ago. 2014. Diário Oficial [da] República Federativa do Brasil. Brasília, DF, 07 de agosto de 2014.

BRIGHAM, Eugene F.; WESTON, J. Fred. Administração Financeira das Empresas. Rio de Janeiro: Ed. Interamericana, 1979.

CALDARELLI, C. E.; BACCHI, M. R. P. Fatores de Influência no Preço do Milho no Brasil. Nova Economia - Belo Horizonte p. 141-164, jan/abr/ 2012. 
Revista Ambiente Contábil - ISSN 2176-9036 - UFRN - Natal-RN. v. 9. n. 1, p. 77 - 96, jan./jun. 2017.

CAlladO, A. L. C.; MIRANDA, L. C.; CAllADO, A. A. C. Fatores Associados à Gestão de Custos: um Estudo nas Micro e Pequenas Empresas do Setor de confecções. Revista Produção v. 13 n. 1, 2003.

CATELli, A.; GUERREIRO, R. Mensuração de Atividades: Comprando "ABC" x “GECON”. Caderno de Estudos FIPECAFI, n08, São Paulo, - abril/1993.

CHURCHILL, Gilbert. Marketing research: methodological foundations. 2a ed. The Dryden Press. 1998.

COMITE GESTOR DO SIMPLES NACIONAL, Simples Nacional, dezembro de 2008.

COTE, J. M., LATHAM, C. K. The Merchandising Ratio: A Comprehensive Measure of Working Capital Strategy. Issues in Accounting Education, v. 14, n. 2, p. 255-267, mai/1999. Disponível em: <http://aaajournals.org/doi/abs/10.2308/iace.1999.14.2.255>. Acesso em: 25 ago 2014.

DELOOF, M. Does Working Capital Management Effect Profitability of Belgian Firm? Journal of Business Finance and Accounting. v.30. n. 3, p. 573-587, 2003.

DOLAN, R. J. Quantity Discounts: Managerial Issues and Research Opportunities. Harvard Business School; Page Range: 1 - 22; February, 1987.

FANELLI, A. F. DEL M.; SANTOS JR., W. R. O Aglomerado Urbano de Jundiaí (SP) e os desafios para a mobilidade metropolitana paulista. Cad. Metrop. São Paulo, v. 15, n. 30, pp. 461-487, jul/dez 2013.

FISHMAN, C. A precificação científica. HSM Management. São Paulo, nº. 39, p. 130-136, $\mathrm{jul} / \mathrm{ago} / 2003$.

FREZATTI, Fábio. Gestão do Fluxo de Caixa Diário: como dispor de um instrumento fundamental para o gerenciamento no negócio. São Paulo: Atlas, 1997.

GODOY, Arilda Schmidt. Pesquisa Qualitativa - Tipos Fundamentais. Revista de Administração de Empresas. São Paulo, v. 35, n.3, p, 20-29 Mai./Jun.1995.

GUERREIRO, R.; FREZATTI. F.; CASADO, T.- Em Busca de um Melhor Entendimento da Contabilidade Gerencial através da Integração de Conceitos da Psicologia, Cultura Organizacional e Teoria Institucional. Revista Cont. Fin.; USP - São Paulo - Edição Comemorativa - p. 7 - 21 - Set/2006.

GUERREIRO, R.; PEREIRA, C.A.; REZENDE, A.J. Em Buscado Entendimento da Formação dos Hábitos e das Rotinas da Contabilidade Gerencial: um Estudo de Caso. Revista de Administração Mackenzie- Volume 7, n. 2, p. 78-101, mai/2006.

HANSEN, Morris H; HURWITZ, William N \& MADOW, William G. Sample survey methods and theory. Vol. I. John Wiley \& sons, Inc. 1966.

JOSE, M. L.; LANCASTER, C.; STEVENS, J. 'Corporate Return and Cash Conversion Cycle'. Journal of Economics and Finance, Vol. 20, 1996, pp. 33-46. 
KASSAI, J. R.; CASA NOVA, S. P. de C. Pequenas Empresas - Como é difícil "levantar dinheiro"! ConTexto, Porto Alegre, v. 6, n. 9, $1^{\circ}$ semestre 2006; ISSN (Impresso): 1676-6016 - ISSN (Online): 2175-8751.

KASSAI, S. As Empresas de Pequeno Porte e a Contabilidade. Caderno de Estudos, FIPECAFI, v.9, n.15, p.60-74, São Paulo, jan/jun/1997.

MASSEI, W. Políticas e Programas de Apoio às Micros, Pequenas e Médias Empresas Industriais: uma Análise de Programas no Estado de São Paulo. Período: 1970- 1986; Dissertação de Mestrado apresentada à Faculdade Estadual de Campinas (UNICAMP) Campinas, 1989.

MATIAS, A. B. Gestão Financeira do Capital de Giro. Cadernos do INEPAD- Instituto de Ensino e Pesquisa em Administração, FEA/USP, Ribeirão Preto, 2006.

MONROE, K. B. Politica de Precios: Para Hacer Rentables las Decisiones; serie MCGRAW - HILL. Traduccion de Carmen Berne y Enrique Giner; Universidad de Zaragoza; España, 1992.

MORRIS, M.; SCHURINK. C. V. E. "Pricing Behavior in Industrial Markets: The Impact of Environmental Dynamics". Journal of Business \& Industrial Marketing, Vol. 8 Iss: 3, pp. $28-43,1993$.

OLIVEIRA, Tania Modesto Veludo de. Amostragem não Probabilística: Adequação de Situações para uso e Limitações de amostras por Conveniência, Julgamento e Quotas. Administração On Line. ISSN 1517-7912. Volume 2, no.3 (julho a setembro de 2001).

PADACHI, K. 'Trends in Working Capital Management and its Impact on Firms Performance: An Analysis of Mauritian Small Manufacturing Firms'. International Review of Business Research Papers, Vol. 2, 2006, pp. 45-58.

PADOVEZE, C. L. Contabilidade Gerencial: um Enfoque em Sistemas de Informação Contábil. $4^{\text {a }}$ edição, São Paulo: Editora Atlas, 2004.

PEREIRA, A. G. C ; SILVA, J.M. ; MOREIRA, C.M. ; BRUNOZI JR, A.C. O Impacto do ICMS-st nas Empresas Optantes pelo Regime do Simples Nacional. In: IX Simpósio de Excelência em Gestão e Tecnologia, Anais ... SEGET, 2012.

PRADO, E. F. S. Formação de Preço como um Processo Complexo. Est. Econ., São Paulo, V. 37, N. 4, P. 745-769, out/dez/2007.

RAHEMAN, A.; NARS, M. Working Capital Management And Profitability - Case Of Pakistani Firms'. International Review of Business Research Papers, Vol. 3, 2007, pp.275296.

RESENDE FILHO, M. de A.; ARAÚJO, FELIPE, A. de; SILVA, ALEXANDRE, S. da. Precificação da Água e Eficiência Técnica em Perímetros Irrigados: Uma Aplicação da Função Insumo Distância Paramétrica. Est. Econ.; São Paulo, v. 41, n. 1, p. 143-172, jan/mar/2011. 
SAINIO, L. M.; MARJAKOSKI, E. The logic of revenue logic? Strategic and operational levels of pricing in the context of software business. Elsevier B. V.; Volume 29, Issue 5, Pages 325-394 May 2009. Technology Management in the Service Economy.

SANTOS, R. V. dos. Planejamento do Preço de Venda. Caderno de Estudos, FIPECAFI, v.9, n.15, p.60 - 74, São Paulo; janeiro/junho 1997.

SERVIÇO BRASILEIRO DE APOIO ÀS MICRO E PEQUENAS EMPRESAS- SEBRAE. Cartilha Tributação, Brasília- DF, 2012.

SERVIÇO BRASILEIRO DE APOIO ÀS MICRO E PEQUENAS EMPRESAS- SEBRAE. Estudo da Mortalidade das Empresas Paulistas; São Paulo- SP, 1999.

SERVIÇO BRASILEIRO DE APOIO ÀS MICRO E PEQUENAS EMPRESAS- SEBRAE. Saiba Mais; Preço de Venda na Prestação de Serviços; Brasília- DF, 2004.

SERVIÇO BRASILEIRO DE APOIO ÀS MICRO E PEQUENAS EMPRESAS- SEBRAE. Doze anos de Monitoramento da Sobrevivência e Mortalidade de Empresas, São Paulo, SP, 2010.

SERVIÇO BRASILEIRO DE APOIO ÀS MICRO E PEQUENAS EMPRESAS- SEBRAE. Causa Mortis. Disponível em: http://www.sebraesp.com.br/arquivos_site/biblioteca/EstudosPesquisas/mortalidade/causa_m ortis_2014.pdf . Acesso em: 16 jan. 2016.

SEBRAE. Mudanças no Supersimples: o que o dono de Pequeno Negócio deve saber; disponível em: http://www.sebrae.com.br/sites/PortalSebrae/artigos/Mudanças-noSupersimples:-o-que-o-dono-de-pequeno-negócio-deve-saber. Visitado em 09/agosto/2014.

SERRA NEGRA, Carlos Alberto. Mensuração Paramétrica do Capital de Giro por Produto. Anais do I Seminário USP de Contabilidade. São Paulo: USP, 2001

SHIN, H. H.; SOENEN, L. 'Efficiency of Working Capital and Corporate Profitability'. Financial Practice and Education, 8, 1998, pp.37-45.

SIDEL, A.; KUME, R. Contabilização das Variações da Necessidade de Capital de Giro. Revista Contabilidade e Finanças - USP, São Paulo, n. 31, p. 66 - 77, jan/abr/2003.

SMITH, K. Profitability versus liquidity tradeoffs in working capital management. In SMITH, K.V. (Ed.), Readings on the Management of Working Capital. West Publishing Company, St Paul,MN, 1980, pp.549-62.

SOARES NETO, A. DE C.; POZO, H.; TACHIZAWA, T. O Capital de Giro como Componente de um Modelo de Gestão no Contexto das Micro e Pequenas Empresas: Estudo em um Segmento Empresarial (CLUSTER) da Indústria Têxtil. REUNA, Belo Horizonte, v.16, n.2, p. 53-70, mai/jun. 2011. ISSN 2179-8834.

SOUZA, A. F. DE; LUPORINI, C. E. M.; SOUZA, M. S. de. Gestão do Capital de Giro. Caderno de Pesquisa em Administração; São Paulo, V. 1, nº 3, 2 Semestre de 1996. 
SOUZA, R.A.; SOUZA, A.A. Gestão do Capital de Giro em Micro e Pequenas Empresas: Estudos de Casos em Empresas do Comércio Varejista de Passos - MG. FACEF Pesquisa; Franca; v.14, n.1, p. 39-51, jan./fev./mar./abr. 2011- ISSN 1516-6503.

STROEHER, A. M.; FREITAS, H. O uso das Informações Contábeis na Tomada de Decisão em Pequenas Empresas. R. Adm. Electronica, São Paulo, v.1, n.1, art.7, jan./jun. 2008.

TERUEL, P. J. G.; SOLANO, P. M. 'Effects of Working Capital Management on SME Profitability'. International Journal of Managerial Finance, vol. 3, 2007, pp. 164-177.

TINOCO, J.E.P. Formação do Preço de Venda; FACCAMP, 2014.

TOLEDO FILHO, J. R. DE; OLIVEIRA, E. L. DE; SPESSATTO, G. Fluxo de Caixa Como Instrumento de Controle Gerencial para Tomada de Decisão: um Estudo Realizado em Microempresas. Revista de Contabilidade do Mestrado em Ciências Contábeis da UERJ (online), Rio de Janeiro, v. 15, n. 2, p. 75 - p. 88, maio/ago., 2010. ISSN 1984-3291.

VIAPIANA, C. Fatores de Sucesso e Fracasso da Micro e Pequena Empresa. In II EGEPE, p. 505-525, Anais .... Londrina/PR, Novembro/2001 (ISSN 1518-4382).

YOSHITAKE, M.;HOJI, M. Gestão de Tesouraria. São Paulo: Atlas, 1997. 